Ann. Zootech., I973, 22 (I), III-II3.

NOTE

\title{
EFFET DE L'ADDITION D'URÉE A UN RÉGIME PAUVRE EN PROTÉINES GHEZ LE LAPIN EN CROISSANCE
}

\author{
F. LEBAS et M. COLIN \\ avec la collaboration technique de G. SARDI \\ Station de Recherches sur l'Elevage des Porcs, \\ Centre national de Recherches zootechniques, I. N. R. A., \\ 78350 Jouy en Josas

\section{RÉSUMÉ}

On a étuclié sur 20 lapereaux californiens àgés de 5 semaines les effets d'une addition d'urée à l'alimentation du Lapin. Les animaux recevaient soit un régime témoin à $\mathrm{2} 2,5 \mathrm{p}$. Ioo de protéines, soit un régime comprenant $\mathrm{r}, 5 \mathrm{p}$. Ioo d'urée en plus des $\mathrm{I} 2,5 \mathrm{p}$. Ioo de protéines.

L'étude du gain de poids, de la consommation et de l'indice de consommation des animaux ne montre aucune différence significative entre les 2 régimes. Malgré le faible taux protéique, les animaux n'ont donc pas utilisé l'urée en quantité mesurable. L'addition d'urée à l'alimentation du Lapin semble donc actuellement sans intérêt, du moins dans les conditions nutritionnelles utilisées.

\section{INTRODUCTION}

Plusieurs études ont mis en évidence l'existence d'une flore uréolytique dans le tube digestif du lapin, en particulier dans l'estomac (VIALLARD et RAYNAUD, ig66) et dans le cacum (Houpt, 1963).

Le Lapin semble done capable de synthétiser des protéines à partir d'urée.

Dans ces conditions, il nous a semblé utile d'étudier les possibilités d'utilisation par le lapin en croissance de quantités importantes d'uréc pour son alimentation azotée.

\section{MATÉRIEL ET MÉTHODES}

Vingt lapereaux californiens des deux sexes, âgés de 5 semaines, ont été élevés en cage individuelle métallique, dans un bâtiment fermé. Les animaux ont reçuà volontédurant 6 semaines soit un régime témoin comprenant 12,5 p. Ioo de protéines, soit le même régime où l'urée, à raison 
de 1,5 p. roo, a été substituée à une fraction d'amidon (tabl. I). Les animaux ont été pesés toutes les semaines le même jour, à la même heure. La pesée de la quantité d'aliments distribués et celle: des refus 3 fois par semaine, a permis de calculer les consommations hebdomadaires et totales.

TABLEAU I

Composition des régimes expérimentaux

\begin{tabular}{|c|c|c|}
\hline Composants en p. 100 & Témoin & Urée (1) \\
\hline Urée $\ldots \ldots \ldots$ & 0 & 1,5 \\
\hline Tourteau soja $44 \ldots \ldots \ldots \ldots$ & 22 & 22 \\
\hline Amidon de Mais $\ldots . \ldots \ldots \ldots \ldots$ & 51 & 49,5 \\
\hline Paille d'Orge $\ldots \ldots \ldots \ldots$ & 20 & 20 \\
\hline Huile de Maïs .............. & 3 & 3 \\
\hline CMV $\ldots \ldots \ldots \ldots \ldots \ldots \ldots$ & 4 & 4 \\
\hline
\end{tabular}

(1) Perlurée 46 p. $100 \mathrm{~N}$.

\section{RÉSUITATS ET DISCUSSION}

Les performances obtenues pour le gain de poids, la consommation et l'indice de consommation (tabl. 2) montrent que l'addition d'urée au régime ne modifie significativemet aucun des 3 critères.

Le gain de poids et la consommation évoluent au cours du temps de façon presque identique pour les 2 régimes. Il n'y a donc pas adaptation des capacités digestives de l'animal à l'apport d'urée.

TABI,EAU 2

Performances moyennes des animaux au cours de l'expérience

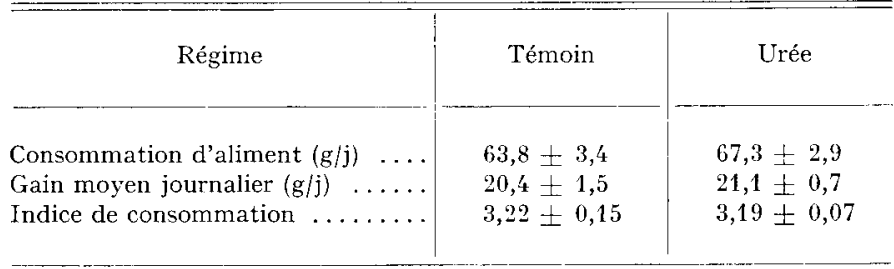

$N$. B. Les valeurs trouvées ne diffèrent significativement pour aucun des 3 critères.

Le régime témoin ne contenait que $12,5 \mathrm{p}$. Ioo de protéines, c'est-à-dire, un taux protéique très inférieur à l'optimum, évalué - pour la protéine de soja - à I7-I 8 p. IOO (LEBAS, I973). De fait, la croissance enregistrée pour l'aliment témoin n'a été que les $2 / 3$ de la croissance normale des lapins de cette souche à cet âge. Une utilisation de l'urée à des fins de synthèse protéique. 
avait donc toute faculté pour se développer. En effet, une utilisation de la totalité de l'urée à des synthèses protéiques correspondrait, dans notre cas, à environ 4,3 points de protéine, ce qui aurait situé les aliments supplémentés à $\mathrm{I} 6,8$ p. Ioo de protéine, soit une valeur proche de l'optimum.

Le lapin semble donc incapable d'utiliser l'urée pour compenser un taux protéique trop faible du régime. Le résultat est en accord avec les expériences menées par OLCESE et PEARson (1948), qui n'ont trouvé aucune amélioration de la croissance par addition de 3,23 p. Ioo d'urée à ro p. Ioo de caséine. Mais, leurs animaux présentant des symptômes d'une carence en vitamine A, leurs résultats étaient sujets à caution.

Notre expérience va également dans le sens đe celle de KING (1971) qui, dans un régime à I 3,5 p. Ioo de protéines, a remplacé une partie de celles-ci par 0,75 p. Ioo d'urée, tout en gardant le même apport azoté. La croissance des animaux du régime expérimental était plus faible que celle obtenue avec le régime témoin. Cependant, cette étude ne permet de conclure qu'à une valorisation éventuelle de l'azote de l'urée, moins bonne que celle des protéines. Au contraire, notre expérience met en évidence une utilisation quasiment nulle de l'urée, mais sans effet toxique apparent. Toutefois, il reste possible de remettre en question nos résultats, car nous n'avons pas la certitude que le régime de base employé soit le plus favorable au développement de la flore digestive. D'autre part, la dose utilisée (I,5 P. Ioo) est peut-être trop forte, un léger effet positif de protéinogenèse étant contrebalancé par un léger effet toxique de l'ammoniaque libérée à la suite des apports importants d'urée.

En conclusion, il semble que dans nos conditions expérimentales, le lapin soit incapable d'utiliser dans son métabolisme des quantités importantes d'azote uréique exogène.

Reçu pour publication en août 1972.

\section{SUMMARY}

\section{EFFECT OF ADDING UREA TO A POOR PROTEIN DIET IN GROWING RABBITS}

The effect of adding urea to the diet was studied in 20 five-weeks-old rabbits. The animaIs received either a control diet (12.5 p. Ioo protein) or a diet contanning I.5 p. Ioo urea + I 2.5 p. Ioo protein.

There was no significant difference between the two diets as regards weight gain, feed intake and feed conversion ratio. In spite of the low protein level the animals did not use measurable amounts of urea. Consequently, under the present nutritional conditions, it does not seem to be interesting to use urea in the feeding of Rabbits.

\section{RÉFÉRENCES BIBLIOGRAPHIQUES}

Hovpt T. R., 1963. Urea utilization by rabbit fed a low protein ration. Am. J. Physiol., 205, Ir44I I 50 .

KING J. O. L., 197I. Urea as a protein supplement for growing rabbits. British Veterinary Journal, 127 (I I), 523-528.

Lebas F., I973. Effet de la teneur en protéines de soja ou de sésame sur les performances de croissance chez le lapin. Ann. Zootech., 22 83-92.

Olchese O., Pearson P. B., I948. Value of urea in the diet of rabbits. Proc. Soc. Exp. Biol. Med., $69,377-379$.

VIALlard V., Raynaud R., 1966. Recherches sur l'utilisation de l'urée par les micro-organismes de l'estomac du lapin. C. R. Soc. Biol., 160, $2478-2483$. 